\title{
Economics as a Science of the Human Mind and Interaction
}

\author{
Michael Fast ${ }^{1}$, Frederik Hertel ${ }^{1}$, Woodrow W. Clark II ${ }^{2}$ \\ ${ }^{1}$ Department of Business and Management, Aalborg University, Aalborg, Denmark \\ ${ }^{2}$ Clark Strategic Partners, Beverly Hills, USA \\ Email: fast@business.aau.dk, fhl@business.aau.dk, wwclark13@gmail.com
}

Received 7 May 2014; revised 4 June 2014; accepted 24 June 2014

Copyright (C) 2014 by authors and Scientific Research Publishing Inc.

This work is licensed under the Creative Commons Attribution International License (CC BY). http://creativecommons.org/licenses/by/4.0/

(c) (i) Open Access

\section{Abstract}

In understanding economics and the organisation of economics, the questions are what constitute economics and the thinking behind economics today? In short what is the field of economics? And in what ways can we connect to and understand this field of study? Of course, the answer to this depends upon the perspective chosen, in which one sees and thinks of economics from a particular philosophical and even political position and perspective. If one takes the perspective on economics from a qualitative paradigm that draws upon the tradition from Kant, Husserl, Simmel, Mead, Schutz, Blumer (see references), then it can be stated that economics cannot only be understood as something that appears in nature. On the contrary, economics must be understood as "something" which results from human behaviour, interaction and groups in human activities and the thinking involved and embedded in those activities. Therefore in analyzing economics it is significant to note that economics belongs to and is being constructed by people due to their everyday lives. What appears as central in those statements, from a qualitative perspective, is that the essences of economics have to be discussed in relation to the mind and thinking related to an understanding of individual and group societal activities. Economics is to be understood as constructed and maintained through everyday human interactions and exchanges, whereby people are creating the meanings of situations with objectives of what are believed as important in the understanding of economics activities, actions and results. Those meanings and definitions of economics are being produced and exchanged in order to become a new comprehensive framework that influences, co-produces, limits and creates contradictions in everyday economic life. This additional qualitative focus [1] outlines the importance of understanding how human cognitions produce meaning of objects, definitions, activities and actions which provides the framework for the field of economics. The epistemological perspective for this is that the objects are not only within themselves. No, instead the objects are as they presents themselves to people, and thereby the meanings we are constructing and attaching to them. The paper will therefore discuss some of the scientific complexities in three areas: mind and thinking; understanding economics as a social activity and construction, and the interplay between economic activities and economic theoretical work. 
Keywords

Economic Thinking, Epistemology, Qualitative Meaning, Language, Discourse, Interaction, Science

\section{Introduction-The Meaning and Making Sense of Economics}

In many areas it makes sense that we have a general and overall view of what economic activities are on a national and global level, and what changes there are in this field over time. These views are descriptions of economics, constructed out from models that the disciplines within social sciences and science had agreed about; or just taken for granted, as useful. They describe economics in a certain way and with a focus in specific areas. In this agreement we have the matter of tradition, history and power that sets the stage and the logic for the conventional agreed-upon construction of science in that era or period of time. There can be a discussion of this tradition as a paradigm [1]-[3] governing the way that mainstream economic thinking is thought and implemented. However it is all based upon a certain set of ontological beliefs and connected epistemology.

There has been a development in economic thinking, but there is still a dominant way of thinking the current mainstream economic perspective. This particular perspective now in the $21^{\text {st }}$ century started in the late $19^{\text {th }}$ century by Milton Friedman [4]-[7], known later in his work as "supply-side economics". There have been shifts in the attention, approach, language, meaning and even the object of this particular approach to economic study. Nonetheless, the creation of a Nobel Prize in Economics, helped to validate it as the dominant approach to economics with awards being made annually in this area, until recently in the last three to four years.

An interesting observation is that this development arises through people from non-economic fields discussing economics like sociology, psychology, anthropology, genetics, and medicine which often do not use evolutionary approaches, behavioral sciences and neuroscience neuroeconomics. The essences of the mainstream economic paradigm is that the thoughts are institutionalized and organised, and have position and power in society and its organizations as several scholars have correctly documented over the past half a century [8]-[11]. People are socialized into thinking in ways, through education and training in certain theories and methods.

Therefore this particular approach in economics to think and socialization is important in several ways in relation to understand economics as a field and how to provide its education. Even though economics has different perspectives, the mainstream conventional logic has a major impact in the theoretical thinking and its practical world.

Consider for example, the performance indicator or key performance indicator (KPI), which is widely used in both private companies and public institutions to measure performance in relation to goals and budgets. In relation to public institutions, this is a part of new public management (NPM) working with the same logic as mainstream economics. The logic is based upon what progress or growth can be measured in figures, statistics or percentages. Then there are correlations and causalities between variables brought into the economic model. Thinking, analyzing and concluding in this way mean that the same economic model is used to both explain the laws of society and used as the tools to control its development. Thus this is a discourse in economics and society [12] whereby rulings are made in both in thinking and acting.

Furthermore the fields of data and the rules in creating this (rule of the) game (and doxa) [13] are accepted by most people. This thinking and socialization can also be seen in an interesting number of cases from a worldwide student association: "the open letter" by international student initiative for pluralism in economics [14]: "It is not only the world economy that is in crisis. The teaching of economics is in crisis too, and this crisis has consequences far beyond the university walls. What is taught shapes the minds of the next generation of policymakers, and therefore shapes the societies we live in. We, 42 associations of economics students from 19 different countries, believe it is time to reconsider the way economics is taught. We are dissatisfied with the dramatic narrowing of the curriculum that has taken place over the last couple of decades. This lack of intellectual diversity does not only restrain education and research. It limits our ability to contend with the multidimensional challenges of the 21st century-from financial stability, to food security and climate change. The real world should be brought back into the classroom, as well as debate and a pluralism of theories and methods. This will help renew the discipline and ultimately create a space in which solutions to society's problems can be generated. United across borders, we call for a change of course. We do not claim to have the perfect answer, but we 
have no doubt that economics students will profit from exposure to different perspectives and ideas. Pluralism could not only help to fertilize teaching and research and reinvigorate the discipline. Rather, pluralism carries the promise to bring economics back into the service of society. Three forms of pluralism must be at the core of curricula: theoretical, methodological and interdisciplinary. Theoretical pluralism emphasizes the need to broaden the range of schools of thought represented in the curricula. It is not the particulars of any economic tradition we object to. Pluralism is not about choosing sides, but about encouraging intellectually rich debate and learning to critically contrast ideas. Where other disciplines embrace diversity and teach competing theories even when they are mutually incompatible, economics is often presented as a unified body of knowledge. Admittedly, the dominant tradition has internal variations. Yet, it is only one way of doing economics and of looking at the real world... An inclusive and comprehensive economics education should promote balanced exposure to a variety of theoretical perspectives, from the commonly taught neoclassically-based approaches to the largely excluded classical, post-Keynesian, institutional, ecological, feminist, Marxist and Austrian traditions - among others. Most economics students graduate without ever encountering such diverse perspectives in the classroom. Furthermore, it is essential that core curricula include courses that provide context and foster reflexive thinking about economics and its methods per se, including philosophy of economics and the theory of knowledge. Also, because theories cannot be fully understood independently of the historical context in which they were formulated, students should be systematically exposed to the history of economic thought and to the classical literature on economics as well as to economic history. Currently, such courses are either non-existent or marginalized to the fringes of economics curricula. Methodological pluralism stresses the need to broaden the range of tools economists employ to grapple with economic questions. It is clear that maths and statistics are crucial to our discipline. But all too often students learn to master quantitative methods without ever discussing if and why they should be used, the choice of assumptions and the applicability of results. Also, there are important aspects of economics which cannot be understood using exclusively quantitative methods: sound economic inquiry requires that quantitative methods are complemented by methods used by other social sciences. For instance, the understanding of institutions and culture could be greatly enhanced if qualitative analysis was given more attention in economics curricula. Nevertheless, most economics students never take a single class in qualitative methods. Finally, economics education should include interdisciplinary approaches and allow students to engage with other social sciences and the humanities. Economics is a social science; complex economic phenomena can seldom be understood if presented in a vacuum, removed from their sociological, political, and historical contexts. To properly discuss economic policy, students should understand the broader social impacts and moral implications of economic decisions..."

It is an interesting open letter by the students in economics, and it underlines what we are talking about. We have experiences in similar curricula models about both thinking economics and teaching economics. What could be gained from this perspective are the essences of "the real world" as lived everyday of life. "Theoretical pluralism" is a scientific reflection and analysis of different theories with the ontology and epistemology for the purpose of being wiser in economic thinking, and correcting the problem that something is missing in studying and understanding the world and its dramatic changes today.

The science of economics is in general, understood as mainstream theory, and based on the tradition of a nomothetic approach [1]. In this search for scientific general laws in economics, the thrust is in two dimensions: theories and the application of them on the one hand, and on data which are presented as numbers and formulas [1]. The tradition in most economic theoretical thinking is a belief in that we over time develop more and more knowledge of the laws of economic. That economic science in the future will develop better and better explanations on those laws and out from this will be better in predicting future events. This logic can be seen in Comte's [15] formulation of positivism in the mid 19 century, the idea of science (uncover the laws) and what it should be and do (governing the society). If we look away from the conditions on which the data are reproductions of the theories, then that data are constructed on what the theories demand in relation to be applied to justify already held beliefs, policies and conditions. Such a theoretical model for data is constructed by the theories themselves [13] [16]. This tautology, of course, is a problem in itself as it merely comes to be the investigation of economic reality from its own definitions, and thereby will be a limitation of what economics otherwise could be.

Another problem that can be raised is on the ontology of economics (which is not specific for just economics, but is general in the social science) and the application of statistic method, which thereby assumes correlations and causalities, rather than stating, researching and validating as with any scientific process. Can social scien- 
tists do their research in the same way as in science? This key argument is the reality of all scientific research, which has a mathematical or formulized structure with its logic. If not, can social scientists stick to a belief that statistics, as a pure method, can produce genuine knowledge and uncover the laws of structure? The problem here is that something precedes the method. However it is rarely discussed in mainstream economic, as it is the tradition for the research documents (doxa and the rule of the game) in the field [1] [13].

What seems to be the case in evaluation of this conventional kind of economics is if the research is done, then the mathematics is correct, not what it is counting. Scientists, however, would never state as proven facts that the hammer builds the house; or that it can tell us something meaningful about the house. Something must precede the hammer: the idea of the house must be seen as reflexions on the situation; the bringing societal knowledge of the concept of the house into play; and the actual bringing the house to completion. In the same way, we cannot state that the house has a meaning in itself, or that the house has the same meaning to everyone. In short the meaning belongs to the subject. The house becoming a reality is not an event for the individual (in modern society). Instead, the house is a matter of integrating ideas, organizing, logistics, economics, laws and regulations, choices and decisions, involving different individuals bringing meaning in using every component over time. This means that they have to construct common meanings through interaction, involving interpretation of each other, negotiating and creating common sense of the situation. So even talking about a concrete and physical object as the house, we have to state that the house has different meanings to all the areas involved in its construction, and only interaction involving understanding of each other over time makes the house possible.

There is also a general view on economics in society that reality has been more complex, globalized, and hence time frames which are accelerating. So economics must be much more and something else than the idea of correlation and causalities. The answers must be in how to integrate complexity in economics, and how to understand it as social interaction with a discussion of the subject and thinking. So to solve those dilemmas we can go to another path, and look into how we think; how we think about economics; and what are the essences of economics from the angle of humanities (social sciences) and the sciences?

\section{Mind and Thinking}

A dimension in the discussion of complexity of economics is connected to the human being. The concept in thinking of economics is and must be related to an idea of what people are. Humans must be seen as mind and body. Humans act in the world and they think of the world [17]-[20]. With the body people move things and place themselves in the world. To act in the world means humans need to orientate themselves in their actions toward what they believe makes sense in their everyday lives, situations in order to take actions. This orientation in the world makes sense since it means that people need to reflect on how they think in everyday situations. Therefore humans must see in what ways the consciousness is constructed and works.

Therefore the idea of how consciousness is and how it is constructing meaning of perception is essential. Kant [18] was of the opinion that all cognition starts with the experience, and that knowledge was a synthesis of experiences and concepts: without sensing humans cannot be aware of any objects (the empirical cognition); without understanding their situations in order to form an opinion of the object (the a priori cognition). In other words, as Kant put it: "There can be no doubt that all our knowledge begins with experience. For how should our faculty of knowledge be awakened into action did not objects affecting our senses partly of themselves produce representations, partly arouse the activity of our understanding to compare these representations, and, by combining or separating them, work up the raw material of the sensible impressions into that knowledge of objects which is entitled experience? In the order of time, therefore, we have no knowledge antecedent to experience, and with experience all our knowledge begins.” ([18], p. 41)

In relation to this, the formulation of the concept of intentionality [19]-[21] is important since the consciousness is the defining property of the mind, that essential property without which the mind could not be. For that reason people can, at the first moment define intentionality as directedness. In saying, that in experiencing an act of consciousness, humans find themselves directed to something. For example, people are directed to the thing or situation perceived. Hence in remembering that they are directed to the event recalled, such as in loving or hating humans who are directed then to the person loved or hated, which continues the interactions [22] [23]. There is no act of thinking without an object that is thought. Hence that act is intentional. No human acts without the willing of something; no act of judgment without something being judge is intentional.

Intentionality, therefore involves an understanding of reality and the cognition of reality. As humans under- 
stand it as the relation of people to reality, intentionality is human consciousness that creates the impressions of the mind and not vice versa. Thus intentionality is the structure in consciousness which gives meaning to the experience. In intentionality, a subject and an object are connected. The consciousness of humans is directed to something else than itself, and this is why neither experiences nor acts and their goals can be separately analyzed. This means that humans think of something, and hence are aware of it in a certain way. This makes humans an active creator of the meaning of object, with intentionality being the processes though which the logic and reality picture of the actor is created. Therefore, intentionality is not the same as intentions, but a dimension lying behind in the consciousness. What is meant is that the very objects are shaped according to the way in which we understand them - the objects do not exist in themselves, i.e. they do not exist with meaning in themselves. This means that humans can in no way acquire knowledge about the objects as they are as such (in themselves).

In this discussion of mind and consciousness, it can be seen that consciousness and meaning are related to sensemaking which researchers [24] [25] note as two different perspectives, but interconnected through the meanings reflected in observable aspects. The first is how human beings make sense or rather percept the world; and secondly how they make sense of their senses or perceptions. In the context of sensemaking, this means something produced retrospectively [21] [24] after action and experience. Meaning or sense is in other words a construction developed in order to understand experiences and actions already been happening. Making sense of ones perceptions means connecting ones basic understandings and expectations towards the world one lives in with ones perceptions.

Perception processes develop certain perception patterns being activated during the reunification with wellknown perception phenomenon. Such perception patterns accelerate future perception processes but they also reducing the speed of and sometimes even challenging [26] the perception of new and previously unknown phenomenon. During the perception of unknown phenomenon the perception process works as an abductive [27] process combining both the development of and the test of hypothesis. In the case of a well-known phenomenon, the perception process is driven by the perception pattern working as a selection process seeking, highlighting and filtering out sensory data. Such perception processes are basically working as deductive processes, where ones knowledge about the immediate object highlights some and leave other sensory data out of consideration. Successful perception processes work as an implicit, and thereby inductive, conformation of the relevance of the existing perception patterns. Such perception processes will therefore include both deductive and inductive elements. This discussion of the circle movement in perception and understanding is central in Gadamer's [28] discussion of understanding and prejudice.

Prejudice is something inevitable and indispensable - it is part of the being of human. Prejudice is the specific manifestation of the historical existence of humans, because history does not belong to them, but humans belong to historical tradition. Long before humans understood themselves through retrospection, they understood themselves in a natural way in family and in society. This belonging to history means that prejudice, far more than humankind's own judgments, is the reality of their being. That is humans enter the world as children, and upbringing and socialization is just to have layer after layer of a prejudice lay on top of each other. Prejudices are indispensable, because mutual understanding rests on prejudices humans also use in interaction: 1) in the situation, where they have common prejudices in respect of a problem or a phenomenon. These prejudices thus create no problems, as humans can immediately understand another person or come to terms with them. 2) In the situation where we are confronted with something new and unfamiliar. When we wonder, we do this by virtue of our prejudices. This is new to us, just because we have no prejudices against it. In this situation a process of understanding can thus be started, with the aim of understanding the new things. Prejudices are thus opening and confirming to understanding, i.e. the precondition of all knowledge and cognition is the preconceived and preliminary meaning of the question. Prejudices may be said to have a treble character of time: 1) they have come to people from tradition and history (before); 2) they are constituent for what people are now and are about to be (now); and 3) they are expectant, being open to future testing and change (future). The epistemologically fundamental question is thus not about how people get rid of prejudices, in order to find a safe foundation of cognition. But it is about how to distinguish fruitful prejudices from unfruitful.

People as an economic beings, should be understood as directed by their intentionality and perception. This means, in many ways, that people are doomed to think in the way they think. Only in reflecting of thinking, can people understand things in a new way. It also means that when people act in economic matters, they perceive economic as an object related to the way they think of it. Hence the tradition and the prejudices of people are a part of it. 


\section{Economics as a Social Activity-The Process of Meaning and Tradition}

It makes no sense to state that people as individuals are constructing the world, or that people collectively are responding to the invisible hand. If this perspective is followed for humans and their thinking, the great challenge in relation to human cognition, perception and communication is to develop a framework for combining the individual perception with the interpersonal interaction and thus the exchange of meaning. Events, actions and objects make sense of by reference to an interpretive scheme or system of meaning [29]. In other words, people understand by reference to representations of reality mapped according to their communicative cartography [30]. This interpretive scheme is developed by combining human interpretations of their experiences combined with what they have (learned) from theories (theoretical or practical descriptions of reality). The ongoing creation of meaning is named semiosis [27] and is understood as a continual process whereby interconnected meaningful creations have affects and replace previous creations of meanings.

The emergence of the immediate object marks the end of the perception process and starts the creation of meaning. This is important since it also marks the transition from the private intrasubjective perception processes to possible intersubjective production and exchange of meanings traditionally named externalization [10]. The Externalization process is an intersubjective negotiation processes [26] where meanings of signs are (re)negotiated, (re)defined and then displaced. The meanings of signs are therefore never conclusively established but open for both ongoing and new negotiations. But even such intersubjective negotiation processes involve subjective perception processes and semiosis (the ongoing construction of meaning). The result of a perception process is a cognitive type which is "something" being connected with a certain meaning such as a nuclear content [26].

Facing an unknown perception phenomenon means that one has not jet created a cognitive type (or concept) for this "something" and therefore neither created a nuclear content for it. In such situations the cognitive processes will switch between the attempt to create a cognitive type and the attempt to create a connected nuclear content. When cognitive types and nuclear contents are created they will automatically affect future processes of perception and cognition. The creation of the cognitive types involves interaction with others. Such intersubjective interactions are cultural formation leading members of the same group to develop and internalize [10] common nuclear content for the cognitive types they individually perceive.

The main force is named successful references [26] and consists of members of the same group suddenly recognising that they share the same relation between their cognitive types, subjectively created, and their nuclear content. The cognitive type is founded on what we above named the immediate object. Cognitive types and nuclear contents can, at a higher level, establish a new expression connected with a new content here named molar content [26]. This means that cognitive types and nuclear content is connected to larger group people and that smaller groups of people might develop a higher level of knowledge reflected in their specialised molar content. The only presupposition for developing such molar content is a certain "language" and thereby specialist knowledge named the molar content.

In society and in research communities, humans therefore have groups of people both developing, exchanging and sharing meaning produced as a result of successful references at a commonsense level of cognitive types and nuclear content as well as developing, exchanging and sharing meaning produced at a higher knowledge level of molar content. Successful references are the results of the subject's perception processes and semiosis developed as a consequence of interpersonal interaction.

Economics is thereby something happening in the mind of humans, and the movement of the body, where they are developing meaning together in relation to making sense of something. It is not only something taking place in the minds of people at varying positions within an organisation but also something taking place in the minds of members of other organisations as customers, universities, banks, unions, governments etc. All these different observers are obviously making different observations depending on their perspectives and positions but they still presuppose that they all been observing the same phenomenon. Members of organisations need space, time, opportunities, and physical contacts in order to execute coordinated acts and interactions maintaining and making sense of actions and activities. Such acts and interactions are corresponding to some kind of common rules [31], generalised other [32], typifications [33] or guidelines shared and internalised by members of the organisation.

Common guidelines for acts and interaction are basically maintaining the understanding of economic actions as both economic, and also as meaningful from an interpretation of them. Expressions as guidelines may indicate ([13], p. 195) that we are dealing with strict rules being far more explicit, conscious, and obeyed than they 
actually are in everyday life. Obviously people choose ([31], p. 142) to follow guidelines and they partly do so in order to obtain a position in the field. One of the reasons for following and integration in groups is described by Cooley's looking-glass-man ([34], p. 93). The looking-glass-man describes how we as human beings presuppose that they in some ways appear to others and that this appearance leads others to make some judgment about them. People might feel pleased or dissatisfied while comparing our self-understanding with the imagined judgments of others.

Since Mead was greatly inspired by Cooley's looking-glass-man, a similar understanding can be found in Mead's "generalized other" ([35], p. 305) because it becomes important in this context since the imagined judgments of others become a main force for integrating and internalisation of the guidelines. Obviously the opposite might [24] happen as well as in the case it creates negative connotations and feedback from in- or outsiders.

Guidelines are not something members voluntarily can choose. Society exist [10] [28], before humans are born in to it and becoming members. This processes of socializing means that the members trying consciously to find some explicit and strong guidelines in order to manage the everyday life. People prefer to describe such guidelines of "natives" as implicit guidance ([13], p. 195) that they, depending on their position and luck can manipulate, interpret and use. In organisation literature there are similar understandings ([1], p. 136) of implicit guidance.

This theoretical turned into reality is similar to a result of shared inspiration running from the understanding of linguistic rules derived from science and found in Noam Chomsky's [8] transformational grammar. "Native" members develop different strategies basically corresponding to their varying symbolic capital [13] [36] produced as a consequence of the positions and opportunities they possess or gain in the field. The character of the symbolic capital present are clearly depending on the context but it is probably basically a consequence of varying social, cultural and economic positions in society.

Since members are neither doomed nor forced to follow guidelines we are in the need of establish a logical division between acts as events and implicit guidance. Such a division is established by following the theoretically division of the self in the "Me" and the "I" [32] [35]. The "Me" is probably best understood as a never ending secondary socialization [10] e.g. connecting experiences of own actions with understanding of others response to these actions and thereby contributing to the ongoing development of the self. This is basically what we recognise as the development of implicit guidance. The "I" is understood as the acting subject in the process of (inter) actions with others (or in the process of intra-action with oneself), and therefore not yet knowing how others or oneself respond to ones acts. The "I" is not independent of the "Me", e.g. making strategies/plans, but the "I" is unable to predict how others or self respond to (inter) actions. When the production and exchange of meaning in the field is seen in this context, meaning becomes something created though a retrospective process.

A similar approach is seen in Weick's [37] revolt against teleological thinking stating that, despite of some peoples tendencies of over-rationalization, intentions is not coming before action but something human beings start looking for after their action. In order to strengthen and develop this argument Weick uses the image of Garfinkel's jurors ([24], p. 10) to describe how human beings create sense retrospectively by looking for clues confirming the meaning they already decided to look for. Put in another way Weick state, with reference to William James, that one's assumptions ([24], p. 38) will affect one's production of meaning. According Weick this means that self-fulfilling prophesies becomes an essential element in the production and exchange of meanings in organisations. This is what Gadamer [28] is discussing in understanding and prejudices.

It might have been a dream becoming a rider on a professional cycling team or just sudden insanity that once made a boy split his bike into atoms. Whatever the reason was, the task definitely seemed must easier while the bike still was in one part. The lesson humans learned from the humiliating trip down to the local bike smith was that the totality and complexity of a bike's spare parts is somehow greater than totality of a bike. Organisational developers too like to break down organisational entireties to spare parts or elements ([38], p. 78) in order to optimise the spare parts and thereby the organisation. Even if an organisation actually followed the presupposition of the systemic approach and consisted of elements or spare parts each of them would probably be more complex than the entirety they once belonged to. An organisational entirety or whole [39] is not apparent in its spare parts or elements.

Instead people should probably recall the fascination when the bike smith reconstructed the entirety of a bike by slowly, carefully and with a deep insight connecting small, and to us, meaningless pieces, bits or better: signs. It is quite obvious that the bike smith is somehow able to see or construct meaning in all the small pieces and 
connect this meaning with his inner image of the bike. Further it is obvious that the bike smith's perception processes might fit the previous description of the connection between perception and construction of meaning. But a model is missing for the creation of meaning following the perception processes.

Pragmatic thinkers have quite similar understandings of how humans produce meaning ([39], p. 100) ([27], p. $492 \mathrm{ff}$ ). But where Peirce has a good definition of a sign and its connection with the production of meaning, others ([39], p. 100) ([11], p. 12) ([35], p. 107) are better to include the social context being a presupposition for the human production of meaning. From the previous visit at the local bike smiths we know that there are at least 3 staff members and a manager at the workshop. Out of these 4 people one is engaged fulltime with managing the workshop and receiving customers while the second are engaged in preparing and fixing motorbikes and only one person is engaged in bicycles. It is quite obvious that the bike smith interact with the rest of the members of the organisation and therefore contribute to the developing, maintaining and changing the workshop but it is also quite obvious that the skills and competences is developed though interaction with others both during his apprenticeship and during his time as journeyman. The competences and skills of the bike smith is basically a result of his ability to produce a certain meaning though his interaction with things (e.g. spare parts etc.) in a certain context (the workshop). The production of meaning is a result of the experiences, skills and competences that have developed during both primary (childhood) and secondary socialization (e.g. apprenticeship). It is a result of a lot of different and interconnected processes e.g. the development of mankind, the raise of an educational system, the general technical development etc.

As mentioned previously, an organisational entirety is a generalisation, and is only possible as long as one is conducting selective perception. Instead of only imagining organisations [40] we could recall our fascination of how a bike smith once slowly, carefully and with deep insight reconstructs the entirety of young boy's bikes. For the boy mentioned as well as for other customers the visit in the local workshop is connected with some kind of existing discursive practise and a discursive order. It is important to avoid reducing the discursive practise to the relation between the work being offered and the price being charged. No doubt that most people consider price and work as important issues but it is only a limited part of the discursive practise existing in a workshop.

One point is the financial and auditing process for public funds, which has now become a very significant issue in the USA. California is an excellent case as the voters in 1999 passed a resolution allowing local school districts to "tax" themselves and thus raise funds for their school buildings. Billions of dollars were raised but the issue was "how" the funds were spent. Several local school districts had cases where officials misrepresented the use of funds. They would provide incomplete and false information. In one, the former superintendent and facility manager were found to have misspent millions of funds resulting in fines to them and the companies that serviced them. The only way that this was uncovered was through a Citizens Oversight Committee who "asked questions" beyond the audited numbers, sought explanations and even did their own due diligence on reports and numbers. The use of interaction and qualitative data showed the depth of the problem so that fines were given and one company settled out of court for $\$ 6.5$ million that was repaid to the school district. Now the key is to create educational programs for other school districts that get the basic areas of economics presented but also the boarder cross-disciplinary fields including law, contraction, engineering and others [10].

The discursive practise constitutes the existing discursive practise and future discursive practises. The discursive order ([41], p. 23) consists of different types of texts or better: standardized ([34], p. 116) social actions [35] involving e.g. customers, employees, employer etc. but also involve a social order or position ([11], p. 73) since everyone has the "...freedom to function in his own way, like the quarter-back, but, in one way or another he has [to some extend] to play the game...” ([39], p. 139). The social order is continually being produced, reproduced and changed during ongoing interactions. Since the social actions are standardized they both follow and reproduce the implicit guidance or ground we mentioned above. Ground is here basically just another way to describe how members of organisations develop a certain perception pattern enabling them to understand and act in correspondence with the common expectations [11] connected to the standardized actions existing in the organisation.

Humans experience an organisation in company with others whom they see and by whom they are seen, which creates an opportunity for "mutual self-recognition". While people do not assume that others experience the organisations in the same ways that others do, they are open to the possibility that others may experiencing something similar and to the idea that people might mutually understand some of what each is experiencing ([42], p. 1637). It might be important to notice that customers, employee, employer etc. during everyday life manage to interact in different discursive practises at varying contexts. This means that the social order as well 
as the discursive practise of the workshop is both influenced by and influence discursive practises taking place in other parts of society.

\section{Interplay between Economic Activities and Theories}

One of Husserl's first comments was that (all) science was characterized by intentionality [19]. The crux here is that we cannot escape ourselves, and that our consciousness and way of thinking always are in play. The argument that the method is neutral holds not for long, since the research project must have to be formulated. Husserl's (who had a mathematical background) conviction was that none of the so-called rigorous sciences, which use mathematical language with such efficiency, could lead towards an understanding of our experiences of the world: a world of the existence of which they uncritically presupposed, and which they pretend to measure by yardsticks and pointers on the scale of their instruments.

All empirical sciences refer to the world as pre-given; but science that their instruments are themselves elements of this world [33]. This means that the reflection on own thinking and paradigmatic taken for granted must be in play, in attempting to grasp economics as a social and individual phenomenon. The tradition creates restrictions and limitations, but also possibilities. The question here is to be aware about both and this means that we in research have to think in understanding of the field of economic, and in the same time of our own self-understanding.

Some economists are beginning to see these links. For example, Dr. Michael Spence has created in his work over 30 years prior as to being a co-winner of the Nobel Prize in Economics in 2001—a "signaling model" which is part of "contract theory" and rooted in Dr. Kenneth Arrow (an earlier co-winner of the Nobel Prize in Economics, 1972) work in the 1960s based on neo-classical economics. While Spence and others who studied with Arrow away from the classical Adam Smith model through looking at other disciplines, the results remain the same. Spence focuses upon how potential employees send a signal about their ability levels due to them acquiring certain educational credentials. The results and conclusions from this quantitative data are very questionable and certainly not complete.

The issue is that there is a need to provide in-depth information than can only be acquired through qualitative methods. To use quantitative information alone in combination with other fields, such as law, makes it even more questionable as to what the demands are for certain interpretations of numbers to meet the needs of law and also public policy which are related to that. Spence (2014) gave a talk at the Stanford University School of Business [43] in China that did just that by explaining the GDP in China was lower (7\%) than it has been over the last decade $(10 \%$ - $11 \%)$ due to the need for "the world's biggest developing country's shift to a more stable and sustainable pace of development". On one level that is correct, but on most others it is wrong: there needs to be a definition of what is "sustainable economic growth" in China today [44]. It is not just growth, but based on what kind of economic and environmental basis. That is not defined and hence leads to policy questions that need to be addressed. The lack of data on the interaction between the people and their government is not documented, researched and analyzed.

The major problem that has to be solved is the distance to the field of economics. Scholars cannot, as discussed, trust strictly on the methods. They must be involved in the field and getting closer. This could be done in several ways: cases, qualitative interviews, storytelling, participant observations, action research, text analyses of document, etc. The matter here is to actually take the issue of validity seriously, and bring back the interpretations and descriptions of the field back to the field. In this way scholars need to insure that their work will be measured by something else then the tradition itself, namely the people involved in and creating the science of economic.

Wittgenstein ([45], p. 107) says, that the border of my language means the border of my world. The matter here is the openness for, and consciousness of, other languages than the one I have. It is not only a problem of distance in space, my language creates both a certain perspective on things and at the same time, it creates a distance in relation to seeing and understanding something else. If essence of economics is to understand the lived experiences by economic actors and the field, we need to reflect, not only in the thinking of the logic we departure from, but also in the language we are using.

\section{References}

[1] Clark, C. and Fast, M. (2008) Qualitative Economics. Coxmoor Publishing Company, Oxford. 
[2] Kuhn, T. (1970) The Structure of Scientific Revolutions. University of Chicago Press, Chicago.

[3] Burrell, G. and Morgan, G. (1980) Sociological Paradigms and Organisational Analysis. Heinemann, London.

[4] Friedman, M. (1962) Capitalism and Freedom. University of Chicago Press, Chicago.

[5] Friedman, M. (1977) Inflation and Unemployment: Nobel Lecture. The Journal of Political Economy, 85, 451-472. http://dx.doi.org/10.1086/260579

[6] Clark, W.W., et al. (2012) BHUSD Bond Fund Annual Report.

[7] Friedman, M. (1957) A Theory of the Consumption Function. Princeton University Press, Princeton.

[8] Chomsky, N. (1975) Reflections on Language. Pantheon Books, New York.

[9] Simmel, G. (1990) The Philosopy of Money. Routledge, London.

[10] Berger, P.L. and Luckmann, T. (1967) The Social Construction of Reality. Anchor Books, New York.

[11] Blumer, H. (1986) Symbolic Interactionism. Perspective and Method. University of California Press, Berkley and Los Angeles.

[12] Foucault, M. (2002) The Archaeology of Knowledge. Routledge, London and New York.

[13] Bourdieu, P. (2002) Outline of a Theory of Practice. Cambridge University Press, Cambridge.

[14] International Student Initiative for Pluralism in Economics—Open Letter (2014). http://www.isipe.net/open-letter/

[15] Comte, A. (1991) Om Positivismen (Discours préliminaire sur l'esprit positif). Korpen, Göteborg.

[16] Fast, M. and Clark, W. (2012) Qualitative Economics-A Perspective on Organization and Economics Science. Theoretical Economics Letters, 2, 162-174. http://dx.doi.org/10.4236/tel.2012.22029

[17] Chomsky, N. (1980) Rules and Representations. Colombia University Press, New York.

[18] Kant, I. (1929) Critique of Pure Reason. Macmillan, London.

[19] Husserl, E. (1962) Ideas. Macmillan, New York.

[20] Merleau-Ponty, M. (1994) The Phenomenology of Perception. Routledge \& Kegan Paul, London.

[21] Schutz, A. (1972) The Phenomenology of the Social World. Heinemann Educational Books, London.

[22] Gurwitsch, A. (1982) Husserl's Theory of the Intentionality of Consciousness. In: Dreyfus, H.L., Ed., Husserl Intentionality and Cognitive Science, The MIT Press, Cambridge, London.

[23] Moustakas, C. (1994) Phenomenological Research Methods. Sage, Thousand Oaks.

[24] Weick, K.E. (1995) Sensemaking in Organizations. Sage Publications, Thousand Oaks.

[25] Gioia, D.A. (2006) On Weick: An Appreciation. Organization Studies, 27, 1709-1721. http://dx.doi.org/10.1177/0170840606068349

[26] Eco, U. (2000) Kant and the Platypus. Vintage, London.

[27] Peirce, C.S. (1998) The Essential Peirce, Vol. 2. Indiana University Press, Bloomington.

[28] Gadamer, H.G. (1993) Truth and Method. Shed \& Ward, London.

[29] Jørgensen, L., Jordan, S. and Mitetrhofer, H. (2012) Sensemaking and Discourse Analyses in Inter-Organizational Research: A Review and Suggested Advances. Scandinavian Journal of Management, 28, 107-120. http://dx.doi.org/10.1016/j.scaman.2012.01.007

[30] Love, S., Ellis, N. and Purchase, S. (2008) Rethinking Language in IMP Research: Networking Processes in Other Words. Scandinavian Journal of Management, 24, 295-307. http://dx.doi.org/10.1016/j.scaman.2008.08.003

[31] Berger, P.L. (1963) Invitation to Sociology. Anchor Books, New York.

[32] Mead, G.H. (1962) Mind Self and Society. The University of Chicago Press, Chicago.

[33] Schutz, A. (1996) Collected Papers, Vol. IV. Kluwer Academic Publishers, Dordrecht. http://dx.doi.org/10.1007/978-94-017-1077-0

[34] Cooley, C.H. (2009) Human Nature and the Social Order. General Books LLC Publication, Danvers.

[35] Mead, G.H. (1984) On Social Psychology. The University of Chicago Press, London.

[36] Friedland, R. (2009) The Endless Fields of Pierre Bourdieu. Organization, 16, 887-917. http://dx.doi.org/10.1177/1350508409341115

[37] Weick, K.E. (1976) Educational Organizations as Loosely Coupled Systems. Administrative Science Quarterly, 21, 1-9. http://dx.doi.org/10.2307/2391875

[38] French, W.L. and Bell, C.H. (1999) Organization Development: Behavioural Science Interventions for Organization Improvement. Prentice-Hall, Upper Saddle River. 
[39] Cooley, C.H. (1998) On Self and Social Organization. The University of Chicago Press, London.

[40] Morgan, G. (1986) Images of Organization. Sage, Bristol.

[41] Fairclough, N. (2001) Language and Power. Longman, Malaysia.

[42] Harquail, C.V. and King, A.W. (2010) Constructing Organizational Identity: The Role of Embodied Cognition. Organization Studies, 31, 1919-0648.

[43] Theil, S. (2014) Michael Spence: China’s Rising Middle. Stanford University Graduate School of Business, Stanford University, Palo Alto.

[44] Clark, W.W. and Isherwood, W. (2010) Special Issue on China: Environmental and Energy Sustainable Development. Utility Policy Journal, 53-61.

[45] Wittgenstein, L. (1993) Tractatus Logico-Philosophicus. Samlarens Bogklub, Denmark. 